\title{
Canada back in the fold?
}

FouR months after the plans of Canadian astronomers to collaborate with their international colleagues in building two 8-metre optical/infrared telescopes seemed to have evaporated, some hope has reemerged.

Earlier this year, the Canadian National Research Council (NRC) said that it could not afford to meet its planned 25 per cent contribution to the \$176-million international Gemini project, which will build twin 8-metre telescopes in Hawaii and Chile (see Nature 351, 680; 27 June 1991). At the time, astronomers in the United States and Britain- - the other two partners in the effort-assumed that Canada was out of the project for good.

But after the first meeting of the Gemini project's managing board - held in Ottawa earlier this month, with Canadian officials present — project leaders are now hopeful that Canada will, after all, join the project. The solution under discussion is for Canada's Natural Sciences and Engineering Research Council to join with NRC in funding the project. With some additional money from a consor- tium of Canadian universities, Canada may be able to take a 15 per cent stake in Gemini. Don Morton, from NRC's Herzberg Institute of Astrophysics, who in June had to write to Canadian astronomers to break the bad news about the Gemini project, is now talking of a possible "reduced, but significant contribution", although he declines to discuss any precise figures. Project scientist Gordon Walker, from the University of British Columbia, believes NRC is responding in part to strenuous lobbying by Canada's astronomers, in particular by postdoctoral and graduate researchers, urging NRC to think again.

Continued Canadian involvement in the project, even at a reduced level, is important to Britain and the United States. British spending on Gemini has already been delayed by two years, and the UK Science and Engineering Research Council is considering a plan to cut several million pounds from the British contribution over the first four years of the project, and to spend this money instead when the telescopes are nearing completion.

Peter Aldhous

\section{OZONE DEPLETION}

\section{London}

EVEN if all nations abide by international controls on ozone-depleting chemicals, ozone loss in mid-latitudes over the next decade may match that experienced in the Antarctic during the 1980 s. This week, a team of leading atmospheric scientists asked by the United Nations Environment Programme (UNEP) to review the damage to the Earth's stratospheric ozone layer warned that reducing these ozone losses will require tighter limits on the emissions of chlorine-containing compounds than those contained in the Montreal Protocol, amended in London only last year.

The review team's assessment assumes that the amended Montreal Protocol will be fully obeyed, although too few countries have so far ratified the amended protocol for it to come into force (the United States and many European countries are among the holdouts). India, which has the potential to be a huge emitter of ozonedestroying chemicals, says that it will only join the protocol once the London amendments have come into effect.

Under the amended Montreal Protocol, the loading of chlorine in the stratosphere will peak at 4.1 parts per billion by volume (ppbv) at the turn of the century, and will not return to 2 ppbv - the concentration at which the Antarctic ozone hole appeared - - until 2060. According to the UNEP review, if chlorofluorocarbons (CFCs), carbon tetrachloride and methyl chloroform are phased out by 1997 , chlorine loading would peak at below 3.9 ppbv, and the atmosphere should return to pre-ozone hole conditions by 2053. (The amended Montreal Protocol calls industrial countries to abandon CFCs and carbon tetrachloride by 2000 and to cease using methyl chloroform by 2005.)

The new UNEP assessment, together the discovery that this year's Antarctic ozone hole is the worst on record, will increase pressure to tighten the Montreal Protocol, when it is reviewed next October. By then, policy-makers should also have the results of a new $£ 14$ million international experiment to study Arctic ozone depletion. The European Arctic Stratospheric Ozone Experiment starts next month, and will involve some 250 researchers from 17 countries.

The aim of the new experiment is to study this winter's Arctic polar vortex, monitoring ozone destruction through the evolution of a single air mass. Researchers hope that these data will convince policymakers that Northern Hemisphere ozone depletion is a serious problem. (Ozone levels north of 40 degrees $\mathrm{N}$ are thought to have declined by 5 per cent between 1970 and 1986.) The experiment, which runs until March 1992, will involve ground-based instruments, research balloons and two aircraft, and is funded by national governments and the European Commission.

\section{European gravity detector in peril}

\section{London}

WHILE US astronomers toast the recent decision of Congress to allow the construction of two gravity-wave observatories in the United States, their colleagues across the Atlantic face the loss of a planned matching detector. The UK Science and Engineering Research Council (SERC) is poised to cancel its proposed $£ 5.5$ million contribution to a $£ \mathbf{4 0}$ million German observatory, a move that would jeopardize the entire project.

Gravity waves are 'ripples' in spacetime, which the theory of general relativity predicts should result from the movement of huge masses in space - the collapse of a star's core during a supernova, for example. The Anglo-German gravity wave detector was one of several projects put under review when SERC ran into financial problems a year ago. Asked to plan its future spending within a strictly limited budget, SERC's ground-based programme committee has now decided that it cannot earmark money for the project.

The observatory's fate is not yet sealed - the decision on the British contribution rests ultimately with SERC's governing council - but the project's supporters are pessimistic. SERC chairman Sir Mark Richmond's public comments on the project have been negative, describing the observatory as an expensive machine designed to perform a single experiment for a small group of researchers (only several dozen British astronomers were expected to be actively involved). Since taking over at SERC, Richmond has made it clear that he wants to reduce SERC's spending on large facilities, except where these are used by a large community of researchers.

If SERC does back out of the gravitywave detector, the German research ministry (BMFT) may abandon the project, say officials in Bonn. BMFT faces its own financial difficulties, with the high costs of German unification affecting all areas of government spending, and is looking for ways to trim its budget.

The loss of the German observatory would leave European hopes for a gravity wave detector pinned on a proposed Franco-Italian collaboration, also yet to receive a firm guarantee of funding. Jim Hough, from the University of Glasgow, and the leading British researcher for the Anglo-German detector, argues that the presence of two European observatories in addition to the US detectors would increase the likelihood of detecting waves from background noise, and help to locate the direction in which they are travelling.

Peter Aldhous 